\title{
Flexible distillation test rig on a laboratory scale for characterization of additively manufactured packings
}

\author{
Johannes Neukäufer ${ }^{1}$, Nadin Sarajlic ${ }^{2}$, Harald Klein ${ }^{2}$, Sebastian Rehfeldt ${ }^{2}$, Heiko \\ Hallmann ${ }^{3}$, Carsten Knösche ${ }^{3}$, and Thomas Grützner ${ }^{1}$ \\ ${ }^{1}$ Ulm University \\ ${ }^{2}$ Technical University of Munich \\ ${ }^{3}$ BASF SE
}

April 10, 2021

\begin{abstract}
Additive manufacturing is increasingly being used to develop innovative packings for absorption and desorption columns. Since distillation has not been in focus so far, this paper aims to fill this gap. The objective is to obtain a miniaturized 3D printed packed column with optimized properties in terms of scalability and reproducibility, which increases process development efficiency. For this purpose, a flexible laboratory scale test rig is presented combining standard laboratory equipment with 3D printed components such as innovative multifunctional trays or the column wall with packing. The test rig offers a particularly wide operating range $\left(F=0.15 \mathrm{~Pa}^{0.5} \ldots 1.0 \mathrm{~Pa}^{0.5}\right)$ for column diameters between $20 \mathrm{~mm}$ and $50 \mathrm{~mm}$. First results regarding the time to reach steady-state, operational stability and separation efficiency measurements are presented using a $3 \mathrm{D}$ printable version of the Rombopak 9M. Currently, innovative packings are being characterized, which should exhibit a optimized bevavior regarding scalability, reproducibility and separation efficiency.
\end{abstract}

\section{Hosted file}

Manuscript.pdf available at https://authorea.com/users/407047/articles/517475-flexibledistillation-test-rig-on-a-laboratory-scale-for-characterization-of-additivelymanufactured-packings 

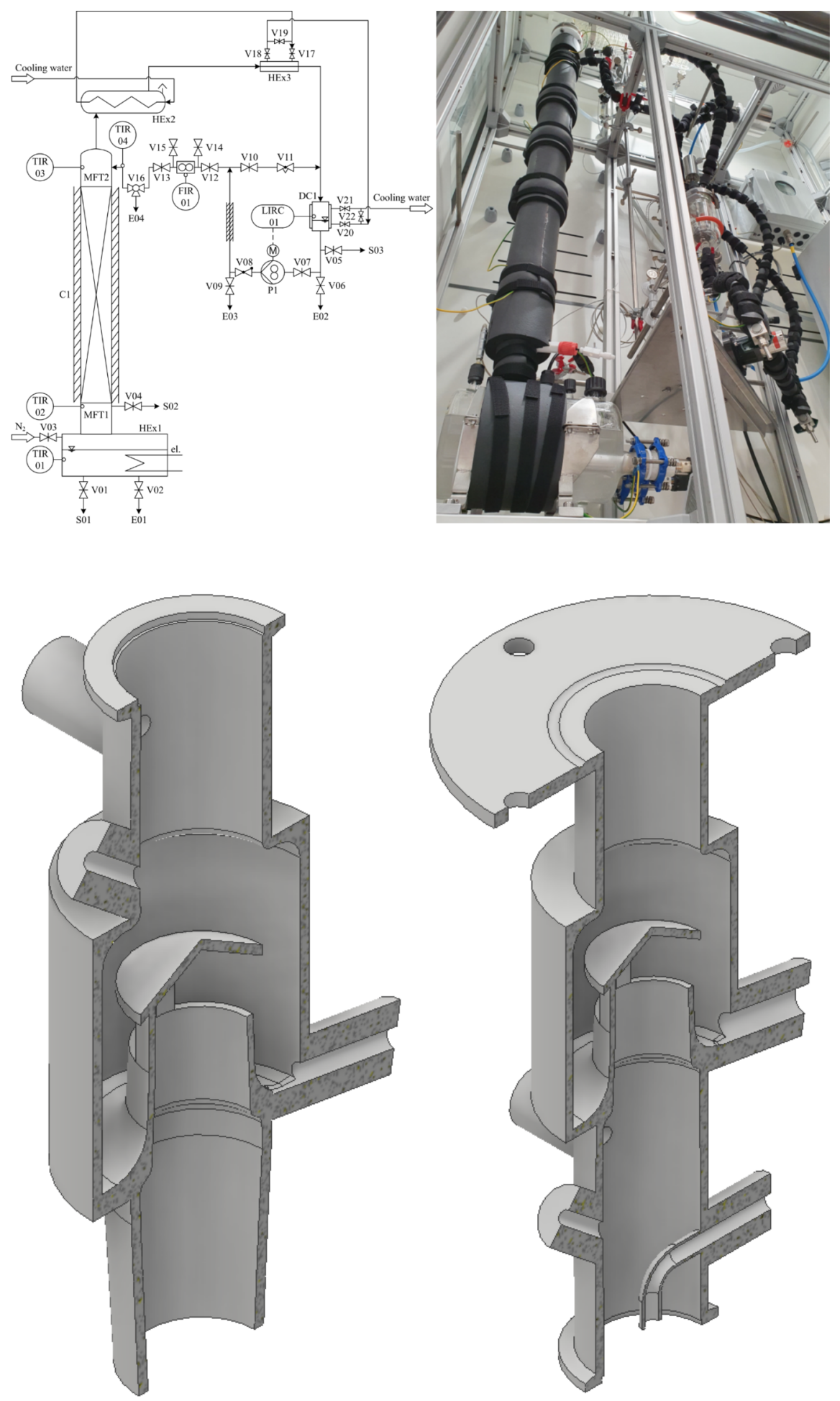

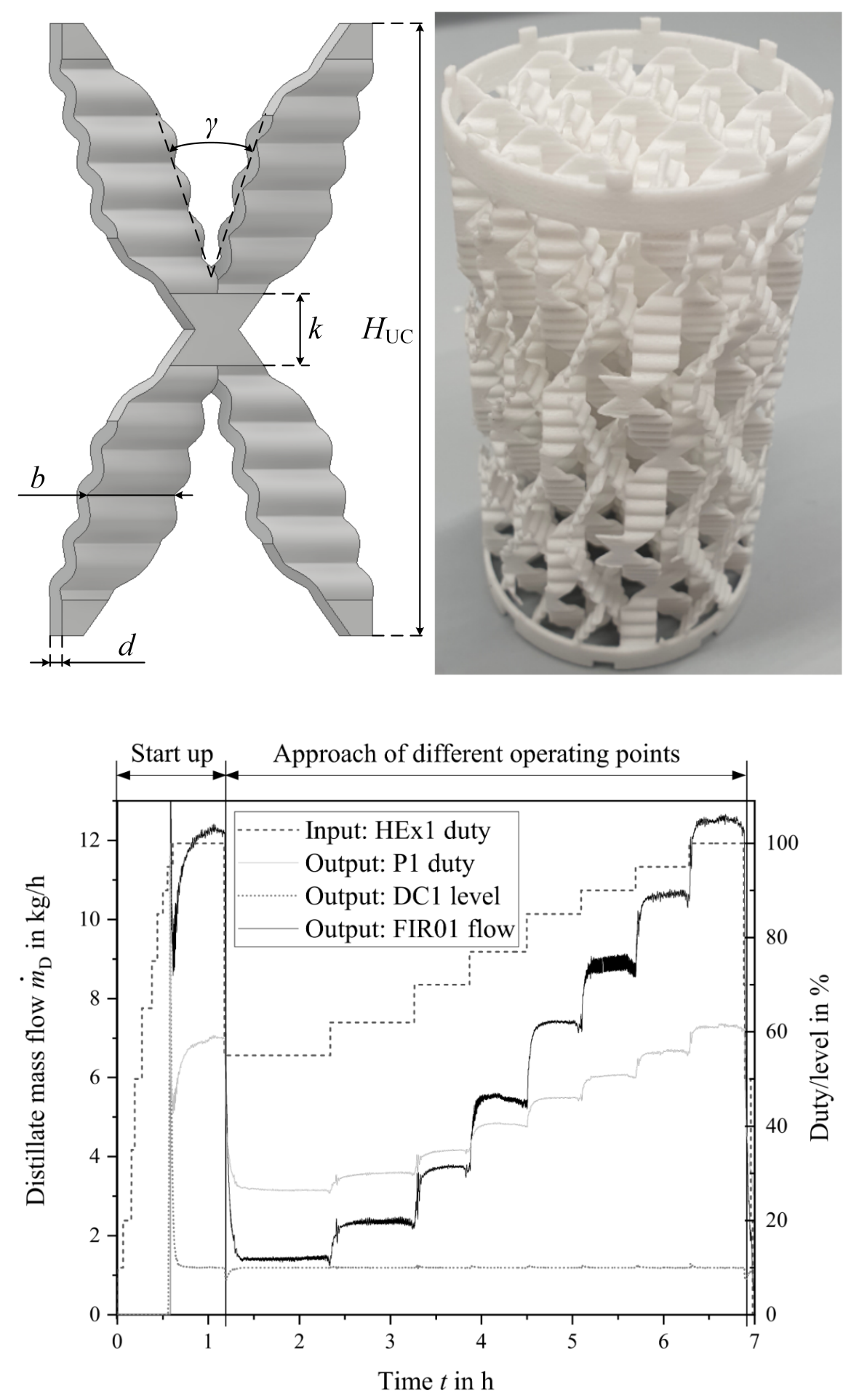

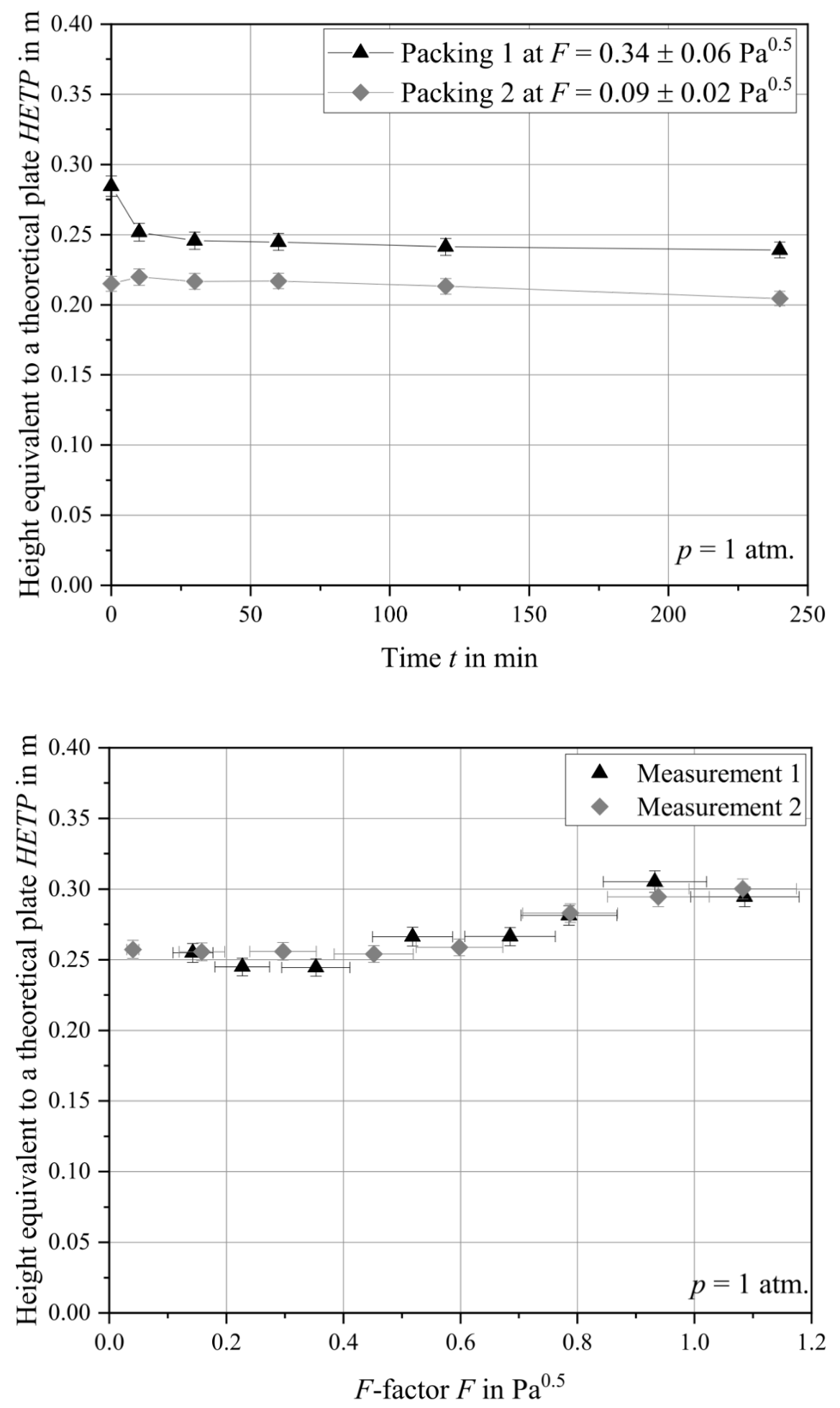


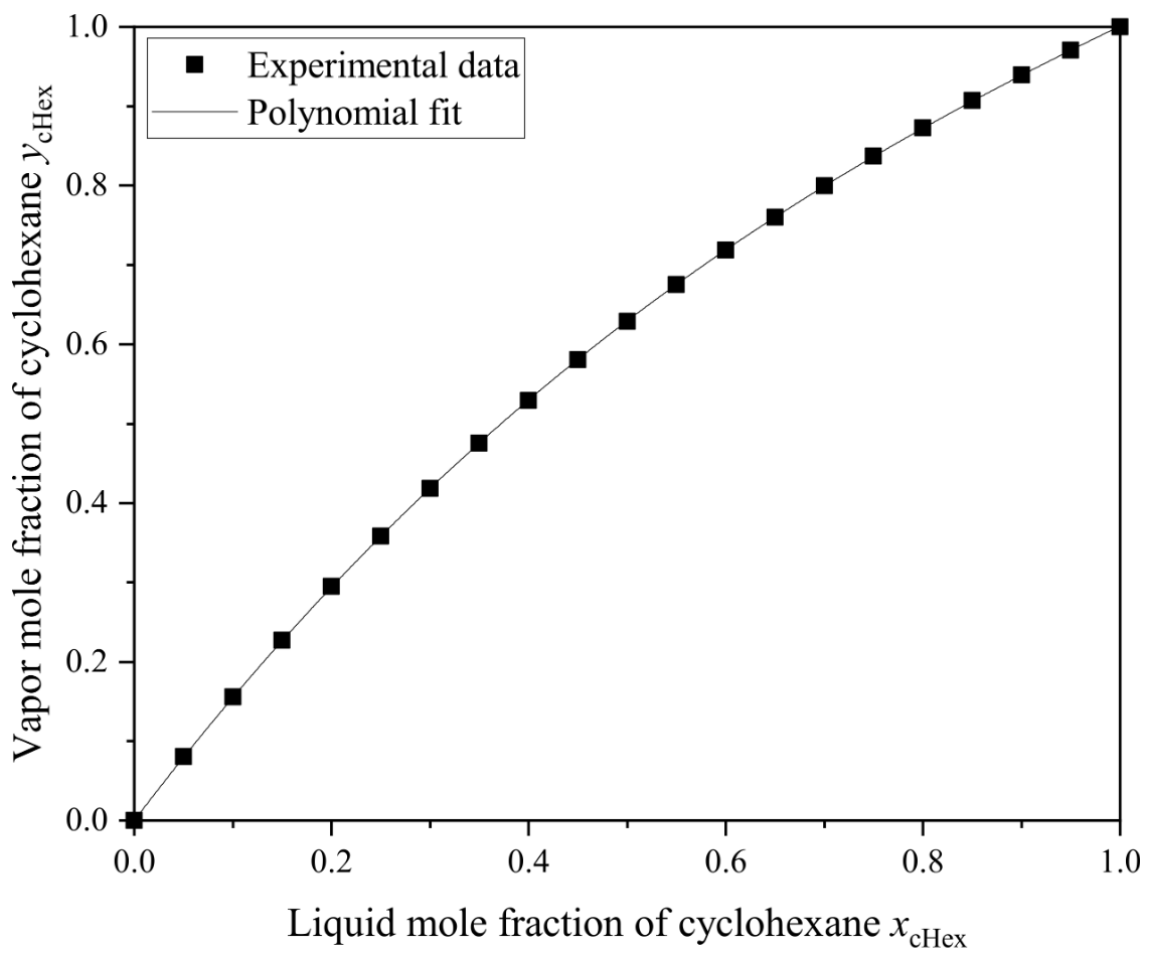

